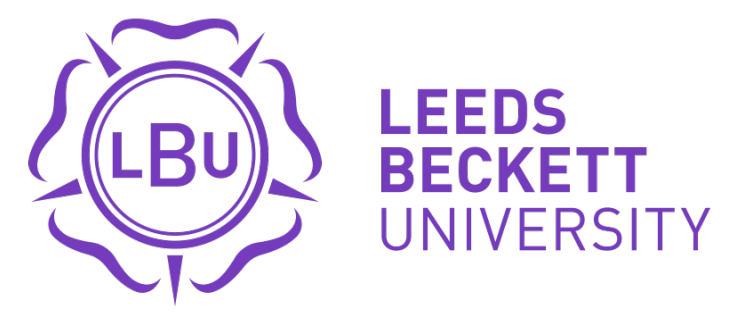

Citation:

Boos, C and Vincent, E and Mellor, A and O'Hara, JP and Newman, C and Cruttenden, R and Scott, P and Cooke, M and Matu, J and Woods, D (2017) The effect of Sex on Heart Rate Variability at High Altitude. Medicine and Science in Sports and Exercise, 49 (12). ISSN 1530-0315 DOI: https://doi.org/10.1249/MSS.0000000000001384

Link to Leeds Beckett Repository record:

https://eprints.leedsbeckett.ac.uk/id/eprint/3921/

Document Version:

Article (Accepted Version)

The aim of the Leeds Beckett Repository is to provide open access to our research, as required by funder policies and permitted by publishers and copyright law.

The Leeds Beckett repository holds a wide range of publications, each of which has been checked for copyright and the relevant embargo period has been applied by the Research Services team.

We operate on a standard take-down policy. If you are the author or publisher of an output and you would like it removed from the repository, please contact us and we will investigate on a case-by-case basis.

Each thesis in the repository has been cleared where necessary by the author for third party copyright. If you would like a thesis to be removed from the repository or believe there is an issue with copyright, please contact us on openaccess@leedsbeckett.ac.uk and we will investigate on a case-by-case basis. 


\section{The effect of Sex on Heart Rate Variability at High Altitude}

Christopher John Boos ${ }^{1,2,3}$, Emma Vincent ${ }^{4}$, Adrian Mellor ${ }^{3-5}$, John O’Hara ${ }^{3}$, Caroline

Newman ${ }^{4}$, Richard Cruttenden ${ }^{4}$, Phylip Scott ${ }^{4}$, Mark Cooke $^{3}$, Jamie Matu ${ }^{3}$, David

Richard Woods ${ }^{4,6,7}$

${ }^{1}$ Department of Cardiology, Poole Hospital NHS Foundation trust, Poole, UK

${ }^{2}$ Dept of Postgraduate Medical Education, Bournemouth University, Bournemouth, UK

${ }^{3}$ Research Institute, for Sport, Physical Activity and Leisure, Leeds Beckett University, Leeds, UK

${ }^{4}$ Defence Medical Services, Lichfield, UK

${ }^{5}$ James Cook University Hospital, Middlesbrough, UK

${ }^{6}$ Northumbria and Newcastle NHS Trusts, Wansbeck General and Royal Victoria Infirmary, Newcastle, UK

${ }^{7}$ University of Newcastle, Newcastle upon Tyne, UK

Key words: sex, high altitude, Heart rate variability, hypoxia

Corresponding author: Dr Christopher J Boos, Department of Cardiology, Poole Hospital NHS Foundation Trust, Longfleet Rd. Poole, Dorset, BH15 2JB

Tel +44 120244 2572; fax +44 1202442754 email: christopherboos@ hotmail.com 


\begin{abstract}
There is evidence to suggest that high altitude (HA) exposure leads to a fall in heart rate variability (HRV) that is linked to the development of acute mountain sickness (AMS). The effects of sex on changes in HRV at HA and its relationship to AMS are unknown.
\end{abstract}

\title{
Methods
}

HRV (5-minute single lead ECG) was measured in 63 healthy adults (41 men and 22 women) aged 18-56 years at sea level (SL) and during a HA trek at 3619m, 4600m and 5140m respectively. The main effects of altitude (SL, 3619, 4600 and 5140m) and sex (men vs women) and their potential interaction were assessed using a Factorial Repeated Measures ANOVA. Logistic regression analyses were performed to assess the ability of HRV to predict AMS.

\section{Results}

Men and women were of similar age (31.2 \pm 9.3 vs $31.7 \pm 7.5$ years), ethnicity, body and mass index. There was main effect for altitude on heart rate, SDNN (standard deviation [SD] of normal-to-normal [NN] intervals), RMSSD (Root mean square of successive differences), NN50 (number of pairs of successive NNs differing by >50 ms), pNN50 (NN50 / total number of NNs), very low frequency (VLF), low frequency (LF), high frequency (HF) and total power (TP). The most consistent effect on post hoc analysis was reduction in these HRV measures between 3619 and 5140m at HA. Heart rate was significantly lower and SDNN, RMSSD, LF, HF and TP were higher in men compared with women at HA. There was no interaction between sex and altitude for any of the HRV indices measured. HRV was not predictive of AMS development.

\section{Conclusions}


Increasing HA leads to a reduction in HRV. Significant differences between men and women emerge at HA. HRV was not predictive of AMS. 


\section{Introduction}

The assessment of heart rate variability (HRV) has rapidly evolved from what was predominantly a research tool to an increasingly appreciated clinical modality (1). Its most widespread translational use at present is in the assessment of psychological stress, physical fitness and the prevention of overtraining $(1,26)$. The improved portability and reduced cost of HRV-measurement equipment have also played a significant role in this regard. HRV assessment relies on the detailed assessment of the variations in the timeintervals between consecutive heart beats which are subject to continuous autonomic control $(26,28)$. From these data, the changes in the beat-beat intervals over time (timedomain analyses) can be more robustly quantified from as little as 1-5 minutes of recording $(1,27,29)$. The beat-to-beat data can be further examined by frequency domain analysis whereby the generated sinusoidal waveforms of these intervals over time, are placed into various frequency components, allowing for a more in depth analysis of autonomic balance $(26,28)$.

An area of recent interest has been in the effects of high altitude (HA) on HRV $(6-8,20)$. HA exposure challenges several physiological systems that are heavily reliant on continuous autonomic control and are likely to influence $\operatorname{HRV}(7,8,21,22)$. Acute hypoxia and HA leads to marked sympathetic activation yet paradoxically there is also evidence of increased competing parasympathetic activity which contributes to the reduction in maximal heart rate in proportion to the altitude gained $(7,8,19,21)$. Hypobaric hypoxia, cold, exercise, stress and fatigue, which are synonymous with HA exposure, are all known individually to influence $\operatorname{HRV}(8,16)$.

There are data to suggest that acute hypoxia and HA exposure leads to a decline in $\operatorname{HRV}(8,20)$ with conflicting data on its potential link to HA-related symptoms and acute mountain sickness (AMS) $(12,13,29)$. Published studies on HRV at HA have been derived from relatively small cohorts, with very little data on the effects of genuine 
terrestrial, rather than simulated HA $(6,12,13)$. Moreover, there has been an underrepresentation of women, in current datasets, despite their obvious physical and potentially important physiological differences compared to men. Resting heart rate tends to be higher in women than men, yet their stroke volumes and cardiac outputs are lower and these differences are sustained and even enhanced with hypoxia $(5,14)$. Resting minute ventilation, which affects $\mathrm{HRV}$, is relatively greater in women under both normoxia and hypoxia (23). Time-domain measures of HRV are typically higher in healthy men $(<50$ years $)$ compared with age-matched women $(5,14,24)$. However, the power spectral density (PSD) of HRV in females is usually characterized by less total power (TP), greater or similar high-frequency (HF) and lower low-frequency (LF) power and $\mathrm{LF} / \mathrm{HF}$ ratios $(14,27,28)$.

There are some data to suggest that women may be also more vulnerable to both AMS development and worsening symptom severity compared with men $(9,18,25)$.

Given the possible sexual dimorphism in HRV and AMS incidence/severity coupled with the reported links between HRV and AMS an investigation of comparative HRV in men and women and its relationship to AMS development is warranted.

In this study, we aimed to investigate, for the first time, the influence of sex on time and frequency-domain measures of HRV with increasing terrestrial HA and its potential link to AMS development.

\section{Methods}

\section{Study design and participants}

Sixty-three healthy British Military servicemen aged >18years were included. They were all assessed at near SL $(<200 \mathrm{~m})$ and again at three further altitudes during progressive HA ascent in the Dhaulagiri region of the Himalayas in March/April 2016. Health status 
was confirmed following a detailed baseline questionnaire. For inclusion, all subjects needed to be low altitude dwellers and were required to be deemed medically fit for HA exposure by their medical practitioners. All participants were required to have successfully completed their mandatory military Personal Fitness Assessment 1.5 mile run in accordance with published standards (adjusted to age and sex) prior to inclusion. This run was undertaken in sports clothing on a flat surface. Subjects with a history of cardiac arrhythmias were excluded. The subjects were studied consecutively in groups of 8-14 at sea level and at HA with a two-day stagger between successive groups. All trekking groups followed an identical ascent and exercise recovery profile with similar morning wake times. Sea level (SL) baseline assessments were performed in the UK approximately six weeks prior to each departure.

\section{High Altitude Ascent and descent profile}

The subjects flew from the UK to Kathmandu (1400m) where they underwent two days of local acclimatisation (Days 1-3). Thereafter, they travelled by road over two days to 1030m (Darbang). From there they commenced trekking on foot over the ensuing 11 days to an altitude of $5140 \mathrm{~m}$ (with an overpass of $5360 \mathrm{~m}$ ) before commencing their decent on foot to Marpha (2719m) and then by road back to Kathmandu. Research assessments were performed at SL and at static research camps at 3619m, 4600m and 5140m during HA ascent.

\section{Physiological Assessments and Heart Rate Variability}

Oxygen saturations $\left(\mathrm{SpO}_{2}\right)$ were measured using a Nonin Onyx (Nonin Medical Inc, Plymouth, Minnesota) pulse oximeter with sampling over approximately 15 seconds. HA-related symptoms were recorded using the Lake Louis Scoring (LLS) system. AMS 
was defined as a LLS of $\geq 3$ in the presence of headache $(11,15)$. HRV assessments were undertaken using dedicated battery-operated portable HRV devices which records a single lead ECG at a sampling rate of 250/second (CheckMyHeart Plus ${ }^{\mathrm{TM}}$ Daily Care Biomedical, Taiwan) as previously described (5). The first of the two surface ECG electrodes were placed at the right sternal edge at one finger breathe below the suprasternal notch and the second over the left $5^{\text {th }}$ intercostal space at the mid clavicular line (i.e. cardiac apex). Measurements were taken on fully rested subjects over a fiveminute period in the early morning post-micturition and prior to breakfast or caffeine (6). All subjects were studied seated in a warm building at sea level and wearing warm clothing and in a tent at HA and were advised not to talk during HRV assessment. All stored recordings were exported via USB hook up for offline data analysis (CheckMyHeart Plus ${ }^{\mathrm{TM}}$ R30 V4, Daily Care Biomedical, Taiwan).

The $\mathrm{R}$ waves of the stored ECG were used as the fucidal point to determine the beat to beat interval with full ECG disclosure. Non-normal-to-normal-(NN) intervals and ectopic beats were identified using customised software non-linear algorithms and were highlighted by colour coding within the HRV software to ease their identification. All ECG data was inspected in six second windows for further identification and manual editing of potential non $\mathrm{NN}$ intervals if necessary. All confirmed non $\mathrm{NN}$ intervals due to ectopy were excluded. The average five-minute heart rate, and the SDNN, RMSSD, NN50 and pNN50 time domain measures, as previously described, were recorded $(26,28)$. The SDNN refers to the standard deviation of the NN intervals from the acquired ECG. The RMSSD (Root mean square of successive differences) is the square root of the mean of the squares of the successive differences between adjacent $\mathrm{NN}$ intervals. The NN50 describes the number of pairs of successive NNs that differ by $>50 \mathrm{~ms}$ and the pNN50 refers to the proportion of NN50 divided by total number of NN intervals. 
Frequency-domain analysis was performed using the non-detrend method of fast Fourier transformation (FFT) with full graphical display of the power spectral data. Key 
frequency band data collected were the HF power $(0.15-0.40 \mathrm{~Hz}), \mathrm{LF}$ power (LF; 0.04$0.15 \mathrm{~Hz}$ ), very low frequency power (VLF; 0.01-0.04 Hz), TP and the LF: HF ratio as previously defined (21,23). Normalized HRV values of LF (LFnu) and HF (HFnu) were calculated as a percentage of the total spectral power minus the VLF respectively (28).

\section{Ethics}

All participation was voluntary and all subjects underwent detailed written informed consent. This study was approved by the Ministry of Defence Research and Medical Ethics Committee (MODREC) and was conducted according to the standards of the Declaration of Helsinki.

\section{Statistical analysis}

Data were analysed using GraphPad InStat version 3.05 and SPSS ${ }^{\circledR}$ statistics version 22 with all graphical figures presented using GraphPad Prism version 4.00 for Windows (GraphPad Software, San Diego, CA, USA). Sample size calculations were performed using a proprietary determined sample size calculator using (GraphPad StatMate version 2.00 for Windows). Data inspection and the Kolmogorov-Smirnov test was undertaken to assess normality of all continuous data, which were presented as mean \pm standard deviations and as the standard error of the mean (SEM) for figures.

Categorical variables were compared using a Chi-Squared test. Comparison of unpaired data was performed using an independent $\mathrm{t}$ test and a Mann-Whitney test for parametric and non-parametric data respectively. Correlations were performed using Pearson and Spearman rank correlation $( \pm 95 \%$ confidence interval, $\mathrm{CI})$ for parametric and nonparametric data respectively. A Factorial Repeated Measures ANOVA with Bonferroni correction (to minimise type I error) was performed to assess the main effect of sex (men vs women) over the four altitude time points (SL, 3619m, 4600m and 5140) and any 
interaction of altitude $\mathrm{x}$ sex on HRV scores. Binary logistic regression analyses (enter) were undertaken to assess potential continuous HRV and other univariate predictors of AMS development (yes or no) and its coefficient (B). We also undertook an additional exploratory analysis of the categorical HRV measures of RMSSD <30ms, LF:HF >1.3 and LFnu $<20 \%$ that have been previously reported to be associated with AMS $(12,13)$. Non-parametric data was log (Ln) transformed and normality confirmed for the ANOVA and logistic regression analyses. A two tailed $\mathrm{P}$ value $<0.05$ was considered statistically significant for all comparisons.

\section{Sample size calculations}

In a recent pilot study in Dhaulagiri, which included 12 subjects, we observed a nonsignificant but $11 \%(-7.9 \mathrm{~ms})$ fall in the RMSSD time domain measure of HRV from baseline to 3600m, using identical HRV (CheckMyHeart Plus ${ }^{\mathrm{TM}}$ ) devices (6). Hence, by studying an even greater altitude of $>5000 \mathrm{~m}$ we calculated that a sample size of $>18$ subjects in each group (men vs women) would have $>80 \%$ power to detect a significant change in the RMSSD at HA at a significance level (alpha) of 0.05 (two-tailed). In another recent study Saleem et al documented that the SDNN was significantly higher in 27 healthy men versus 18 healthy women (24). We estimated that a sample size of at least 18 women and >30 men studied across four differing altitudes would have sufficient power to detect a significant sex difference in HRV including SDNN.

\section{Results}

HRV data were available on 62 subjects at SL and at $3619 \mathrm{~m}$ and on 58 subjects at $4600 \mathrm{~m}$ and $5140 \mathrm{~m}$ respectively. The men $(31.2 \pm 9.3$ years $)$ and women $(31.7 \pm 7.5$ years $)$ were well matched for age, ethnicity, smoking history and body mass index (table 1). As 
expected, the men were on average taller and heavier with higher systolic blood pressures at baseline, with faster completion times for their mandatory annual 1.5 mile running fitness test $(\mathrm{P}<0.0001)$ (table 1$)$.

HA exposure led to a significant fall in $\mathrm{SpO}_{2}$ and an increase LLS among both men and women, compared to baseline with no effect for subject sex (table 2). Heart rate (five-minute average) increased at HA in both sexes, with women having consistently higher rates than men both at SL and at HA (table 2 and 4).

There was a significant main effect for altitude on all time-domain measures of HRV. On post-hoc analysis this represented a significant reduction in time-domain measures of HRV most consistently between $3619 \mathrm{~m}$ to $5140 \mathrm{~m}$ (table 2 and 4; figure 1). There was a significant main effect for altitude on LF, HF and TP. This difference was again most marked on post-hoc analyses between $3619 \mathrm{~m}$ and $5140 \mathrm{~m}$ where significant reductions in LF, HF and TP were observed (table 3 and 4; Figures 2).

Time domain measures of HRV were non-significantly higher in men at SL and significant differences emerged at HA, where all measures were notably higher in men (table 2 and 4; figure 1). There was also a main effect for sex among the frequency domain measures of TP, LF and HF power which were all significantly higher in men at HA (table 3 and 4, figure 2). There were no interactions between sex (men vs women) $\mathrm{x}$ altitude (SL, 3619m, 4600m and 5140m) on any measures of HRV (table 4) or heart rate.

$\mathrm{SpO}_{2}$ inversely correlated with LLS $(\mathrm{r}=-0.38 ; 95 \% \mathrm{CI}-0.50$ to $-0.24 ; \mathrm{p}<0.0001)$ and positively with RMSSD ( $r=0.16 ; \mathrm{p}=0.02)$, SDNN ( $\mathrm{r}=0.18 ; 0.05$ to $0.30: \mathrm{p}=0.007)$, $\operatorname{VLF}(\mathrm{r}=0.17 ; 0.04$ to $0.30 ; \mathrm{p}=0.01), \mathrm{LF}(\mathrm{r}=0.16 ; 0.03$ to $0.29 ; \mathrm{p}=0.2)$ and $\mathrm{TP}(\mathrm{r}=0.17$; 0.03 to $0.29 ; \mathrm{P}=0.02)$.

The prevalence of AMS increased at HA from $15.2 \%$ at $3619 \mathrm{~m}$ to $27.3 \%$ at $4600 \mathrm{~m}$ and $32.5 \%$ at $5140 \mathrm{~m}(\mathrm{p}=0.004)$. Reducing $\mathrm{SpO}_{2}(\mathrm{~B}-0.13 ; \mathrm{P}<0.0001)$ and 
increasing altitude (B 0.80; $\mathrm{P}<0.0001)$ and mean heart rate $(\mathrm{B} 0.03 ; \mathrm{P}=0.04)$ were the only univariate predictors of AMS. None of the continuous measured HRV parameters or the categorical variable of subject sex (men vs women) were predictive of AMS. RMSSD $<30 \mathrm{~ms}$, LF:HF $>1.3$ and LFnu $<20 \%$ were not predictive of or associated with AMS.

\section{Discussion}

This is the largest study to assess the effects of HA on HRV, and to the author's knowledge the first study to investigate the influence of sex on HRV at terrestrial HA. In this study HRV was influenced by HA. Minor sex-related differences in HRV that were observed at SL were sustained at genuine terrestrial HA. A link between HRV and symptoms of AMS were not found.

We observed a significant fall in resting $\mathrm{SpO}_{2}$ and an increase in LLS with increasing HA. There was also a significant main effect for altitude on heart rate (which increased) and all the evaluated time-domain measured of HRV. The most consistent change was between 3619 and 5140m, and hence at higher altitude, where there was a significant fall in SDNN, RMSSD, NN50, PNN50, LF and HF power. These findings are in keeping with published data that has shown a fall in time-domain measures of HRV at HA $(12,13,29)$. These changes are in part explained by a number of factors linked to the HA environment. These include reducing sleep quality, extremes of cold and heat, physical exhaustion and increasing anxiety which are all known to adversely affect and reduce time domain measures of $\operatorname{HRV}(13,19,30)$.

We also observed a significant main effect for sex on heart rate and time domain measures of HRV at HA, with men having consistently higher scores and greater variability. This is a novel finding. Whilst published data has shown a consistent trend to 
higher time domain measures of HRV in young adult men versus women at SL $(3,14,24)$. This is the first comparative study at HA. The trend to higher time domain HRV measures at SL became significant at HA. There was no interaction of altitude on sex on the time domain HRV parameters. This finding can be partly explained by the sex differences in heart rate which was consistently lower in the men. Heart rate is well known inversely correlate with all main time domain measures of HRV (28).

We also observed a significant effect of altitude (SL, 3619m, 4600m and 5140m) on TP, VLF, LF and HF power. The most consistent finding, on post-hoc analyses was a reduction in these parameters at the highest altitude of $5140 \mathrm{~m}$ vs sea level and $3619 \mathrm{~m}$. HA exposure was also associated with a significant main effect of sex with greater TP, LF and HF power among the men. Results from a very recently published meta-analysis of comparative HRV measures among men and women at SL, that included more than 60,000 participants, demonstrated that when compared to that seen in women, PSD in men is generally characterised by lower HF power and greater LF, TP and LF/HF ratios (14). This is thought to reflect their higher resting sympatho-vagal tone (hence greater LF and LF/HF ratios) compared with women. Our LF data supports this previous data. However, contrary to the published data we found that HF power was actually higher with variable effects on $\mathrm{LF} / \mathrm{HF}$ power among the men. There are several potential factors that might explain these results. It is known that LF, HF power and their relative ratios (LF/HF) can be markedly influenced by a number of factors which include age, respiratory rate, recording length and heart rate $(3,14,23,26,28)$. Whilst the ages were similar between the men and the women the greater heart rates in women would have led to the analysis of a higher number of beat-to-beat intervals, despite an identical recording period, which could be an important confounder. Secondly, whilst increasing heart rate and minute ventilation are HA are thought to relate to enhanced sympathetic activation there is also evidence of elevated parasympathetic neural activity $(4,7,21,22)$. This increase in competing vagal activation at HA is thought to contribute to the reduction in 
maximal heart rate at HA (7). LF power and the LF/HF ratio have been traditionally thought to represent sympathetic activation and net sympatho-vagal balance respectively with RMSSD and HF power reflecting parasympathetic nerve activity (28). However, there is evolving evidence to show that these arbitrary assumptions about the discrete autonomic effects these HRV measures, may be overly simplistic (2).

Our identified sex-related dissimilarities in the time and frequency domain HRV measures at HA could also relate to differences in fitness levels. Indeed, the men in our study had higher time domain measures of HRV and lower 1.5 mile run times. Our findings could also relate dissimilarities in acclimatisation in men vs women. Acclimatisation encompasses the cumulative effects of multiple factors such as hydration, ventilation and enuresis that are known to influence autonomic balance and HRV (10). HRV, and in particular frequency domain analysis can be significantly affected by breathing pattern and ventilation, which are markedly affected HA where hypoxia driven hyperventilation predominates $(14,17,18)$. In our study paced breathing during HRV assessments were not performed, but the participants were encouraged to relax and breathe normally. The majority of published studies on HRV at HA have utilised spontaneous non-paced breathing, hence were keen to utilise a comparative methodology $(7,9,10,24)$. Our participants were assessed at far higher altitudes and under greater hypoxia than most of the previous HA HRV studies to date, hence the potential challenge to paced breathing was likely to have been greater. We anticipated that at 4600 and 5140m controlled breathing under significant hypoxia and a high ventilatory drive might paradoxically increase subject anxiety and perceived breathlessness. By enforcing a similar paced breathing protocol in both men and women we risked neutralising genuine sex-related differences in HRV related to well-reported dissimilarities in ventilation between men and women at HA $(2,19)$. Unfortunately, we did not measure comparative respiratory rate and ventilation among the men vs women. 
This is an obvious limitation as sex-related differences in their spontaneous breathing it could have provided further insight into the observed differences in HRV identified.

We did not observe a link between AMS and HRV in this current study. There is limited evidence linking changes in HRV to AMS, raising the prospect of using HRV as a non-invasive predictor of AMS development $(9,10)$. In a previous study Karinen et al investigated 36 different healthy climbers ascending from $2400 \mathrm{~m}$ to $6300 \mathrm{~m}$ altitudes during five differing expeditions and noted that a lower RMSSD and HF at 2400m was a marker of AMS at 3000 to $4300 \mathrm{~m}$ (10). However, contrary to our study, the speed of ascent varied between their five studied groups. Furthermore, they measured HRV over two rather than five minutes. In another study, of similar size $(n=32)$, Hang et al noted that a $\mathrm{HF} \%<20 \%(\mathrm{nu})$ or $\mathrm{LF} / \mathrm{HF}$ ratio $>1.3$ at lower altitudes was predictive of AMS at 3400m (9). These HRV parameters failed to be either associated or predict AMS in or study. Willie et al in a prolonged normobaric hypoxia study and our group in another recent study (ithlete RMSSD-derived HRV score), failed to identify a clear link between AMS and HRV supporting our data $(16,23)$.

The potential reasons for the contradictory findings in HRV to predict AMS may relate to differences in study design, HA environment, ascent/hypoxic profile, HRV recording time as well as the actual HRV parameters measures. Even the definitions of AMS that were used differed between these studies. For example, Karinen et al defined AMS as a LLS of $\geq 3$ in their study whereas in the study by Willie they a LLS $\geq 4$ was used to define AMS $(10,24)$. In our study we used the Lake Louise Consensus definition (1992) for AMS, which is refers to LLS score of $\geq 3$ in the presence of headache $(4,8,12)$. It is well known that AMS is a highly complex and heterogeneous condition. Its causative mechanisms include changes in cerebral arterial blood flow and increased vascular permeability within the blood brain barrier, both of which may be influenced by 
local autonomic control (18). Whilst HRV reflects overall cardiac autonomic control it is relatively non-specific and is not indicative of local autonomic balance $(2,18)$. 
This study has several additional imitations that should be mentioned. The subjects were studied in consecutive groups of 8-14 two days apart and not all together in one batch. This was because of the large sample size for this type of remote field study and the need to undertake at HRV in the early morning pre-breakfast and caffeine. We measured five minute HRV which may be more vulnerable to short-term sex and situational bias than that obtained from longer recordings (22). However, five minute HRV measurement is well-validated and endorsed by the current HRV Task Force Guidelines and is more potentially applicable to clinical practice than that of longer recordings (22). We included a larger proportion of men than women and cannot exclude the possibility of sample bias, despite their similarities in age, ethnicity, smoking history and body mass index.

In conclusion our findings indicate that increasing HA was associated with a reduction in HRV which was most notable at $4600 \mathrm{~m}$ and above. There were significant sex related differences in HRV between men and women which were sustained at HA. There was no interaction between sex and altitude on any of the HRV parameters measured. These sex-related differences may reflect dissimilarities in their autonomic balance and acclimatisation to HA. HRV was not predictive of AMS.

\section{Acknowledgments}

The authors would like to thank the Surgeon General. We also like to sincerely thank the subjects for their time and for volunteering to take part in this study.

\section{Sources of Funding}


This projected was funded by a variety of sources and the main funders include the Royal Centre for Defence Medicine, a grant from the Royal Navy Royal Marines Charity (RNRMC) and the Poole Hospital Cardiac Research Fund.

\section{Disclosures}

Professor Boos has received speaker's fee and consultation fees from Pfizer, Bristol Myers Squibb, Astra Zeneca and Boehringer-Ingelheim. Professor Mellor has received speaker fees from Medtronic. The other authors report no conflicts. 


\section{References}

1. Bellenger CR, Fuller JT, Thomson RL, Davison K, Robertson EY, Buckley JD. Monitoring Athletic Training Status Through Autonomic Heart Rate Regulation: A Systematic Review and Meta-Analysis. Sports Med. 2016; 46(10): 1461-86.

2. Billman GE. The LF/HF ratio does not accurately measure cardiac sympathovagal balance. Front Physiol. 2013; 4(26):1-5.

3. Bonnemeier H, Richardt G, Potratz J, Wiegand UK, Brandes A, Kluge N, Katus HA. Circadian profile of cardiac autonomic nervous modulation in healthy subjects: differing effects of aging and sex on heart rate variability. $\mathbf{J}$ Cardiovasc Electrophysiol. 2003; 14(8):791-9.

4. Boos CJ, O'Hara JP, Mellor A, Hodkinson PD, Tsakirides C, Reeve N, Gallagher L, Green ND, Woods DR. A Four-Way Comparison of Cardiac Function with Normobaric Normoxia, Normobaric Hypoxia, Hypobaric Hypoxia and Genuine High Altitude. PLoS One. 2016; 11(4): e0152868.

5. Boos CJ, Mellor A, O'Hara JP, Tsakirides C, Woods DR. The Effects of Sex on Cardiopulmonary Responses to Acute Normobaric Hypoxia. High Alt Med Biol. 2016 Jun;17(2):108-15. doi: 10.1089/ham.2015.0114. Epub 2016 Mar 23.

6. Boos CJ, Bakker-Dyos J, Watchorn J, Woods DR, O'Hara JP, Macconnachie L, Mellor A. A comparison of two methods of heart rate variability assessment at high altitude. Clin Physiol Funct Imaging. 2016 Jan 14. doi: 10.1111/cpf.12334. [Epub ahead of print].

7. Boushel R, Calbet J-AL, Rådegran G, Søndergaard MS, Wagner PD, Saltin B. Parasympathetic neural activity accounts for the lowering of exercise heart rate at high altitude. Circulation 2001; 104: 1785-1791. 
8. Buchheit M, Richard R, Doutreleau S, Lonsdorfer-Wolf E, Brandenberger G, Simon C. Effect of acute hypoxia on heart rate variability at rest and during exercise. Int J Sports Med. 2004; 25(4): 264-9.

9. Canouï-Poitrine F, Veerabudun K, Larmignat P, Letournel M, Bastuji-Garin S, Richalet JP. Risk prediction score for severe high altitude illness: a cohort study. PLoS One. 2014 ;9(7):e100642. doi: 10.1371/journal.pone.0100642. eCollection 2014.

10. Dishman RK, Nakamura Y, Garcia ME, Thompson RW, Dunn AL, Blair SN. Heart rate variability, trait anxiety, and perceived stress among physically fit men and women. Int J Psychophysiol. 2000; 37(2):121-33.

11. Hackett, P.H. \& Oelz, O. The Lake Louise consensus on the quantification of altitude illness. In: Sutton JR, Houston CS \& Coates G (eds) Hypoxia and Mountain Medicine: Queen City Printers, Burlington, VT 1992: 327-330.

12. Huang HH, Tseng CY, Fan JS, Yen DH, Kao WF, Chang SC, Kuo TB, Huang CI, Lee $\mathrm{CH}$. Alternations of heart rate variability at lower altitude in the predication of trekkers with acute mountain sickness at high altitude. Clin J Sport Med. 2010; 20(1): 8-63.

13. Karinen HM, Uusitalo A, Vähä-Ypyä H, Kähönen M, Peltonen JE, Stein PK, Viik J, Tikkanen HO. Heart rate variability changes at $2400 \mathrm{~m}$ altitude predicts acute mountain sickness on further ascent at 3000-4300 m altitudes. Front Physiol. 2012; 336.

14. Koenig J, Thayer JF. Sex differences in healthy human heart rate variability: A meta-analysis. Neurosci Biobehav Rev. 2016; 64: 288-310.

15. Lake Louise Consensus on Definition and Quantification of Altitude Illness In: Sutton JR, Coates G, Houston CS. (eds.) Hypoxia: Mountain Medicine. Burlington, Vermont: Queen City Press; 1992: 327-330. 
16. Liu W, Lian Z, Liu Y. Heart rate variability at different thermal comfort levels. Eur J Physiol. 2008; 103 (3):61-6.

17. Loeppky JA, Scotto P, Charlton GC, Gates L, Icenogle M, Roach RC. Ventilation is greater in women than men, but the increase during acute altitude hypoxia is the same. Respir Physiol. 2001; 125(3): 225-37.

18. MacInnis MJ, Carter EA, Freeman MG, Pandit BP, Siwakoti A, Subedi A, Timalsina U, Widmer N, Thapa GB, Koehle MS, Rupert JL. A prospective epidemiological study of acute mountain sickness in Nepalese pilgrims ascending to high altitude (4380 m). PLoS One. 2013 Oct 9;8(10):e75644. doi: 10.1371/journal.pone.007564

19. Mazzeo RS, Reeves JT. Adrenergic contribution during acclimatization to high altitude: perspectives from Pikes Peak. Exerc Sport Sci Rev. 2003; 31(1): $13-8$.

20. Mellor A, Bakker-Dyos J, O’Hara J, Woods DR, Holdsworth DA, Boos CJ. Smartphone-Enabled Heart Rate Variability and Acute Mountain Sickness. Clin J Sport Med. 2017 Apr 12. doi: 10.1097/JSM.0000000000000427.

21. Paparde A, Plakane L, Circenis K, Aivars JI. Effect of acute systemic hypoxia on human cutaneous microcirculation and endothelial, sympathetic and myogenic activity. Microvasc Res. 2015; 102: 1-5.

22. Richalet JP. Physiological and Clinical Implications of Adrenergic Pathways at High Altitude. Adv Exp Med Biol. 2016; 903: 343-56.

23. Sajkov D, Neill A, Saunders NA, McEvoy RD. Comparison of effects of sustained isocapnic hypoxia on ventilation in men and women. J Appl Physiol (1985). 1997; 83(2): 599-607.

24. Saleem S, Hussain MM, Majeed SM, Khan MA. Sex differences of heart rate variability in healthy volunteers. J Pak Med Assoc. 2012; 62(5): 422-5. 
25. Santantonio M, Chapplain JM, Tattevin P, Leroy H, Mener E, Gangneux JP, Michelet C, Revest M. Prevalence of and risk factors for acute mountain sickness among a cohort of high-altitude travellers who received pre-travel counselling.Travel Med Infect Dis. 2014;12(5): 534-40.

26. Sassi R, Cerutti S, Lombardi F, Malik M, Huikuri HV, Peng CK, Schmidt G, Yamamoto Y. Advances in heart rate variability signal analysis: joint position statement by the e-Cardiology ESC Working Group and the European Heart Rhythm Association co-endorsed by the Asia Pacific Heart Rhythm Society. Europace. 2015; 17(9): 1341-53.

27. Sztajzel J, Jung M, Bayes de Luna A. Reproducibility and sex-related differences of heart rate variability during all-day activity in young men and women. Ann Noninvasive Electrocardiol. 2008; 13(3): 270-7.

28. Task Force of the European Society of Cardiology and the North American Society of Pacing and Electrophysiology. Heart rate variability: standards of measurement, physiological interpretation and clinical use. Circulation 1996; 93: 1043-65.

29. Wille M, Mairer K, Gatterer H, Philippe M, Faulhaber M, Burtscher M. Changes in cardiac autonomic activity during a passive 8 hour acute exposure to $5500 \mathrm{~m}$ normobaric hypoxia are not related to the development of acute mountain sickness. Int J Sports Med. 2012; 33(3): 186-91.

30. Woo JM, Kim TS. Sex plays significant role in short-term heart rate variability. Appl Psychophysiol Biofeedback. 2015; 40(4): 297-303. 


\section{Legends for Figures}

Figure 1 Comparative Changes in the RMSSD (mean \pm SEM) among men and women at sea level and increasing high altitude. Post-test differences on repeated measures ANOVA: $*$ versus sea level, $\$ 3619$ vs $5140 \mathrm{~m}, \uparrow 3619$ vs $4600 \mathrm{~m}$.

Figure 2 Comparative Changes in Low frequency (LnLF) Power (mean \pm SEM) among men and women at sea level and increasing high altitude. Post-test differences on repeated measures ANOVA: * versus sea level, $\$ 3619$ vs $5140 \mathrm{~m}$. 


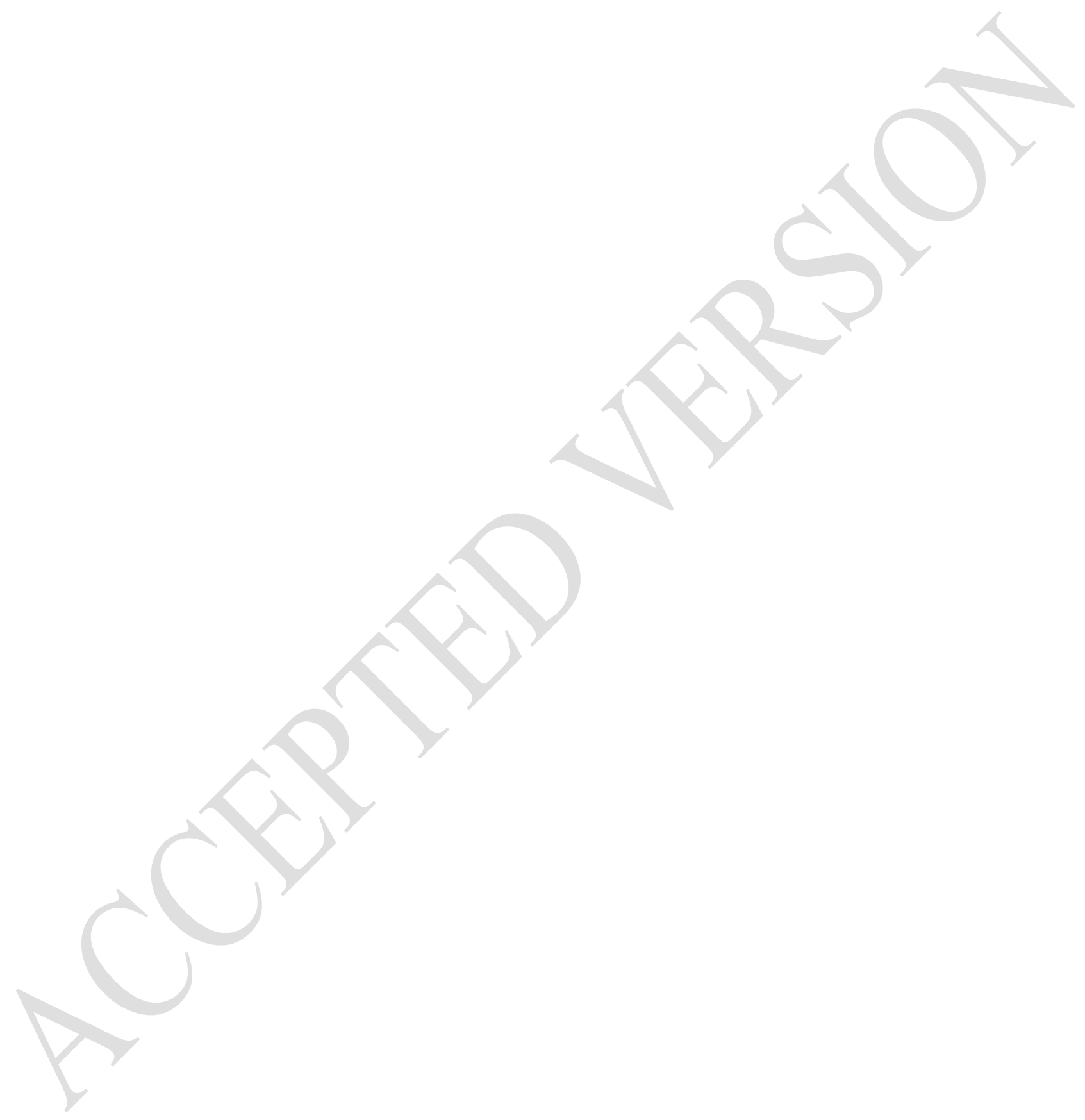


Table 1: Baseline Demographics

\begin{tabular}{|c|c|c|c|c|}
\hline Demographic & Overall & Men & Women & $\mathbf{P}$ value* \\
\hline Number (\%) & $63(100 \%)$ & $41(65 \%)$ & $22(35 \%)$ & \\
\hline Age, years (range) & $31.41 \pm 8.7(18-56)$ & $31.2 \pm 9.3$ & $31.7 \pm 7.5$ & 0.83 \\
\hline Height $(\mathrm{cm})$ & $173.4 \pm 9.7$ & $177.1 \pm 9.3$ & $166.5 \pm 5.8$ & $<0.0001$ \\
\hline Weight $(\mathrm{kg})$ & $72.5 \pm 13.0$ & $77.4 \pm 12.1$ & $63.2 \pm 9.3$ & $<0.0001$ \\
\hline Body mass index, $\mathrm{kg} / \mathrm{m}^{2}$ & $24.0 \pm 2.8$ & $24.2 \pm 3.0$ & $23.5 \pm 2.6$ & 0.36 \\
\hline $\begin{array}{l}\text { Systolic blood pressure } \\
(\mathrm{mmHg})\end{array}$ & $132.1 \pm 15.6$ & $136.9 \pm 15.1$ & $123.7 \pm 12.7$ & $<0.0001$ \\
\hline $\begin{array}{l}\text { Diastolic blood pressure } \\
(\mathrm{mmHg})\end{array}$ & $80.5 \pm 14.6$ & $80.8 \pm 12.4$ & $78.7 \pm 10.7$ & 0.53 \\
\hline $\begin{array}{l}\text { Basic fitness test time } \\
\text { (minutes) }\end{array}$ & & $9.5 \pm 1.1$ & $10.8 \pm 1.2$ & $<0.0001$ \\
\hline $\begin{array}{l}\text { Hormonal contraception } \\
\text { (pill / implant) }\end{array}$ & & 0 & $5(22.7 \%)$ & $<0.0001$ \\
\hline $\begin{array}{l}\text { Ethnicity, \% } \\
\text { - Caucasian } \\
\text { - Non Caucasian }\end{array}$ & $\begin{array}{l}56(88.9 \%) \\
7(11.1 \%)\end{array}$ & $\begin{array}{l}35(85.4 \%) \\
6(14.6 \%)\end{array}$ & $\begin{array}{c}21(95.5 \%) \\
1(5.5 \%)\end{array}$ & 0.40 \\
\hline $\begin{array}{l}\text { Smoking status }(\%) \\
\text { - Never } \\
\text { - Current } \\
\text { - Ex }\end{array}$ & $\begin{array}{c}51(81.0 \%) \\
4(6.3 \%) \\
8(12.7 \%)\end{array}$ & $\begin{array}{c}33(80.4 \%) \\
4(9.8 \%) \\
4(9.8 \%)\end{array}$ & $\begin{array}{c}18(81.8 \%) \\
0(0 \%) \\
4(18.2 \%)\end{array}$ & 0.23 \\
\hline
\end{tabular}


Table 2 Changes in $\mathrm{SpO} 2$ and time domain measures of Heart rate Variability at sea level to increasing high altitude

\begin{tabular}{|c|c|c|c|c|c|}
\hline & Sea level & 3619m & $4600 \mathrm{~m}$ & $5140 \mathrm{~m}$ & $\begin{array}{l}\text { Post-test Paired } \\
\text { differences for } \\
\text { effects of altitude }\end{array}$ \\
\hline \multicolumn{6}{|l|}{$\mathrm{SpO} 2(\%)$} \\
\hline -Men & $97.7 \pm 1.3$ & $93.1 \pm 3.2$ & $83.5 \pm 6.0$ & $81.3 \pm 5.3$ & \\
\hline -Women & $97.9 \pm 1.3$ & $90.9 \pm 4.5$ & $80.4 \pm 8.5$ & $78.6 \pm 5.4$ & \\
\hline \multicolumn{6}{|l|}{ Lake Louis Scores } \\
\hline -Men & $0.4 \pm 0.6$ & $1.0 \pm 2.1$ & $1.9 \pm 2.2$ & $1.5 \pm 1.5$ & $a b c$ \\
\hline -Women & $0.5 \pm 0.9$ & $1.5 \pm 2.4$ & $2.3 \pm 1.2$ & $1.3 \pm 1.4$ & \\
\hline \multicolumn{6}{|l|}{ Mean heart rate/minute } \\
\hline -Men & $57.6 \pm 9.0$ & $63.6 \pm 12.0$ & $72.7 \pm 15.2$ & $74.5 \pm 15.7$ & abcde \\
\hline -Women & $60.8 \pm 9.7$ & $69.5 \pm 9.4$ & $79.5 \pm 12.8$ & $81.1 \pm 11.8$ & \\
\hline \multicolumn{6}{|l|}{ SDNN (ms) } \\
\hline -Men & $78.1 \pm 25.2$ & $94.8 \pm 55.9$ & $85.0 \pm 451.7$ & $72.1 \pm 49.2$ & abcde \\
\hline -Women & $76.0 \pm 28.3$ & $74.6 \pm 29.1$ & $52.5 \pm 20.8$ & $51.4 \pm 28.0$ & \\
\hline \multicolumn{6}{|l|}{ RMSDD (ms) } \\
\hline -Men & $67.0 \pm 31.6$ & $93.2 \pm 72.9$ & $76.2 \pm 56.4$ & $62.2 \pm 54.6$ & cde \\
\hline -Women & $59.6 \pm 32.2$ & $60.8 \pm 30.2$ & $37.3 \pm 19.5$ & $41.5 \pm 32.6$ & \\
\hline \multicolumn{6}{|l|}{ NN50 } \\
\hline -Men & $104.8 \pm 38.6$ & $113.0 \pm 76.0$ & $105.5 \pm 75.2$ & $81.9 \pm 64.0$ & ce \\
\hline -Women & $96.3 \pm 54.6$ & $104.8 \pm 59.1$ & $54.4 \pm 51.4$ & $60.0 \pm 65.3$ & \\
\hline \multicolumn{6}{|l|}{ pNN50 (\%) } \\
\hline -Men & $37.8 \pm 19.8$ & $39.6 \pm 27.8$ & $34.1 \pm 25.6$ & $26.5 \pm 22.2$ & cde \\
\hline -Women & $32.8 \pm 19.8$ & $32.2 \pm 18.8$ & $14.7 \pm 14.3$ & $16.4 \pm 18.8$ & \\
\hline
\end{tabular}

Results of post hoc paired differences with time (altitude) for both men and women: a, sea level vs $3619 \mathrm{~m}$; b sea level vs $4600 \mathrm{~m}$; c sea level vs $5140 \mathrm{~m}$; d, $3619 \mathrm{~m}$ vs $4600 \mathrm{~m}$; e, 3619 vs $5140 \mathrm{~m}$; $4600 \mathrm{~m}$ vs $5140 \mathrm{~m}$ 
Table 3 Changes Frequency domain measures of Heart rate Variability at sea level to increasing high altitude

\begin{tabular}{|c|c|c|c|c|c|}
\hline & Sea level & 3619m & 4600m & $5140 \mathrm{~m}$ & $\begin{array}{l}\text { Post-test Paired } \\
\text { differences for } \\
\text { effects of altitude }\end{array}$ \\
\hline \multicolumn{6}{|l|}{ Total power $\left(\mathrm{ms}^{2}\right)$} \\
\hline -Men & $7.87 \pm 0.7$ & $7.95 \pm 1.4$ & $7.86 \pm 1.6$ & $7.34 \pm 1.5$ & cef \\
\hline -Women & $7.75 \pm 0.7$ & $7.73 \pm 0.8$ & $7.05 \pm 0.7$ & $7.0 \pm 1.0$ & \\
\hline \multicolumn{6}{|l|}{$\operatorname{VLF}\left(\mathrm{ms}^{2}\right)$} \\
\hline -Men & $6.06 \pm 0.7$ & $6.11 \pm 1.2$ & $6.00 \pm 1.3$ & $5.62 \pm 1.3$ & ce \\
\hline -Women & $6.16 \pm 0.8$ & $5.92 \pm 0.9$ & $5.44 \pm 0.7$ & $5.28 \pm 1.1$ & \\
\hline \multicolumn{6}{|l|}{$\operatorname{LnLF}\left(\mathrm{ms}^{2}\right)$} \\
\hline -Men & $6.80 \pm 0.8$ & $6.61 \pm 1.4$ & $6.62 \pm 1.7$ & $6.19 \pm 1.4$ & ce \\
\hline -Women & $6.44 \pm 0.7$ & $6.67 \pm 1.0$ & $5.89 \pm 0.9$ & $5.76 \pm 1.0$ & \\
\hline \multicolumn{6}{|l|}{$\operatorname{LnHF}\left(\mathrm{ms}^{2}\right)$} \\
\hline -Men & $6.55 \pm 0.8$ & $6.87 \pm 1.7$ & $6.50 \pm 2.1$ & $6.09 \pm 1.8$ & $\mathrm{e}$ \\
\hline -Women & $6.23 \pm 1.0$ & $6.36 \pm 0.9$ & $5.47 \pm 1.0$ & $5.43 \pm 1.3$ & \\
\hline \multicolumn{6}{|l|}{$\mathrm{LF} \%, \mathrm{nu}$} \\
\hline -Men & $55.4 \pm 15.9$ & $44.7 \pm 18.0$ & $52.7 \pm 17.9$ & $52.0 \pm 18.8$ & NS \\
\hline -Women & $44.5 \pm 18.8$ & $56.8 \pm 15.6$ & $58.8 \pm 16.4$ & $56.8 \pm 20.6$ & \\
\hline \multicolumn{6}{|l|}{$\mathrm{HF} \%, \mathrm{nu}$} \\
\hline -Men & $44.6 \pm 15.9$ & $55.4 \pm 18.0$ & $47.3 \pm 17.6$ & $48.0 \pm 18.8$ & NS \\
\hline -Women & $45.7 \pm 18.4$ & $43.2 \pm 15.6$ & $41.2 \pm 16.4$ & $43.2 \pm 20.6$ & \\
\hline \multicolumn{6}{|l|}{$\mathrm{LF} / \mathrm{HF}$} \\
\hline -Men & $1.7 \pm 1.3$ & $1.0 \pm 0.80$ & $1.6 \pm 1.5$ & $1.6 \pm 1.5$ & NS \\
\hline -Women & $1.4 \pm 1.1$ & $1.6 \pm 1.0$ & $2.1 \pm 1.8$ & $2.2 \pm 2.2$ & \\
\hline \multicolumn{6}{|c|}{$\begin{array}{l}\text { NS, Non-significant; Results of post hoc paired differences with time for men and women } \\
\text { combined: a, sea level vs } 3619 \mathrm{~m} \text {; b sea level vs } 4600 \mathrm{~m} \text {; c sea level vs } 5140 \mathrm{~m} \text {; d, } 3619 \mathrm{~m} \text { vs } \\
\text { 4600m; e, } 3619 \text { vs } 5140 \mathrm{~m} \text {; f } 4600 \mathrm{~m} \text { vs } 5140 \mathrm{~m}\end{array}$} \\
\hline
\end{tabular}


Table 4 Results of Two-way Repeated Measures ANOVA comparing the main effects of altitude (SL, 3619m, 4600m and 5140m) and sex (men vs women) on measures of heart rate variability

\begin{tabular}{|c|c|c|c|c|c|c|}
\hline & \multicolumn{2}{|c|}{ Time (altitude) } & \multicolumn{2}{|c|}{ Sex } & \multicolumn{2}{|c|}{ Interaction } \\
\hline & $\mathrm{F}$ & $P$ value & $\mathbf{F}$ & $P$ value & $\mathbf{F}$ & P Value \\
\hline $\mathrm{SpO}_{2}$ & 165.20 & $<0.001^{\text {abcef }}$ & 0.49 & 0.48 & 0.21 & 0.89 \\
\hline Lake Louis Scores & 4.30 & $0.008^{\mathrm{abc}}$ & 0.37 & 0.55 & 0.63 & 0.60 \\
\hline Mean heart rate & 47.3 & $<0.001^{\text {abcde }}$ & 4.10 & 0.04 & 0.43 & 0.73 \\
\hline SDNN & 40.6 & $<0.001^{\text {abcde }}$ & 4.00 & 0.04 & 1.14 & 0.26 \\
\hline RMSDD & 8.10 & $<0.001^{\text {cde }}$ & 4.40 & 0.04 & 0.94 & 0.43 \\
\hline NN50 & 8.20 & $<0.001^{\text {ce }}$ & 3.20 & 0.08 & 0.82 & 0.47 \\
\hline PNN50 & 10.7 & $<0.001^{\text {cde }}$ & 3.50 & 0.06 & 0.94 & 0.41 \\
\hline $\mathrm{SD} 1 / \mathrm{SD} 2$ & 1.89 & 0.13 & 4.90 & 0.03 & 0.34 & 0.80 \\
\hline Total power & 8.40 & $<0.001^{c}$ & 4.20 & 0.04 & 1.87 & 0.14 \\
\hline VLF & 7.10 & $<0.001^{\mathrm{ce}}$ & 2.00 & 0.17 & 1.76 & 0.16 \\
\hline LF & 7.10 & $<0.001^{\text {ce }}$ & 3.80 & 0.048 & 1.70 & 0.17 \\
\hline $\mathrm{HF}$ & 5.80 & $0.001^{\mathrm{e}}$ & 5.80 & 0.02 & 1.26 & 0.29 \\
\hline LFnu & 0.39 & 0.76 & 3.10 & 0.09 & 1.70 & 0.17 \\
\hline HFnu & 0.39 & 0.76 & 3.10 & 0.09 & 1.70 & 0.17 \\
\hline LF / HF & 0.50 & 0.70 & 1.60 & 0.20 & 3.50 & 0.07 \\
\hline
\end{tabular}

$\mathrm{SpO}_{2}$, oxygen saturations; Results of post hoc paired differences with time (altitude) a, sea level vs $3619 \mathrm{~m}$; b sea level vs $4600 \mathrm{~m}$; c sea level vs $5140 \mathrm{~m}$; d, $3619 \mathrm{~m}$ vs $4600 \mathrm{~m}$; e, 3619 vs $5140 \mathrm{~m}$; f $4600 \mathrm{~m}$ vs $5140 \mathrm{~m}$ 


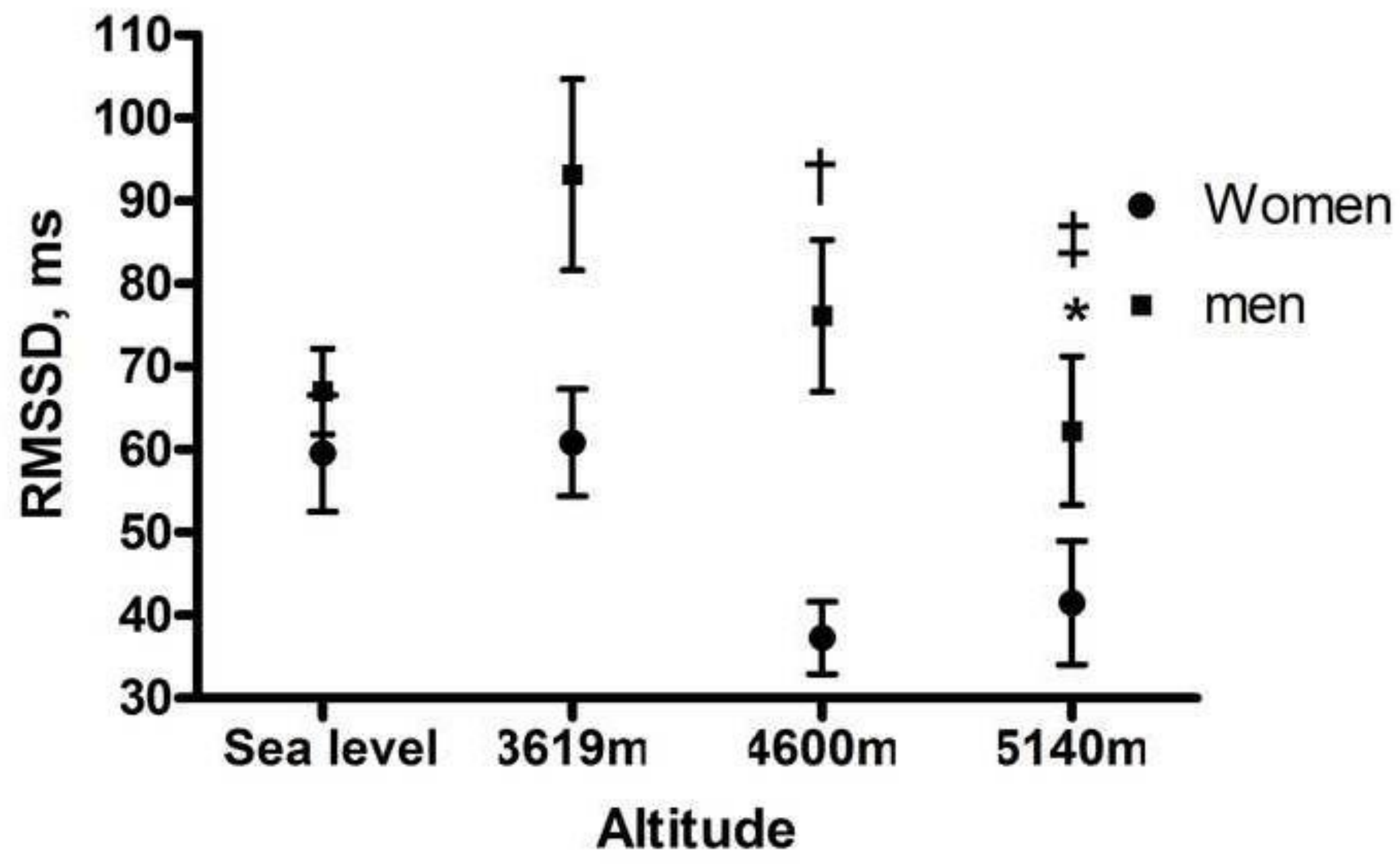




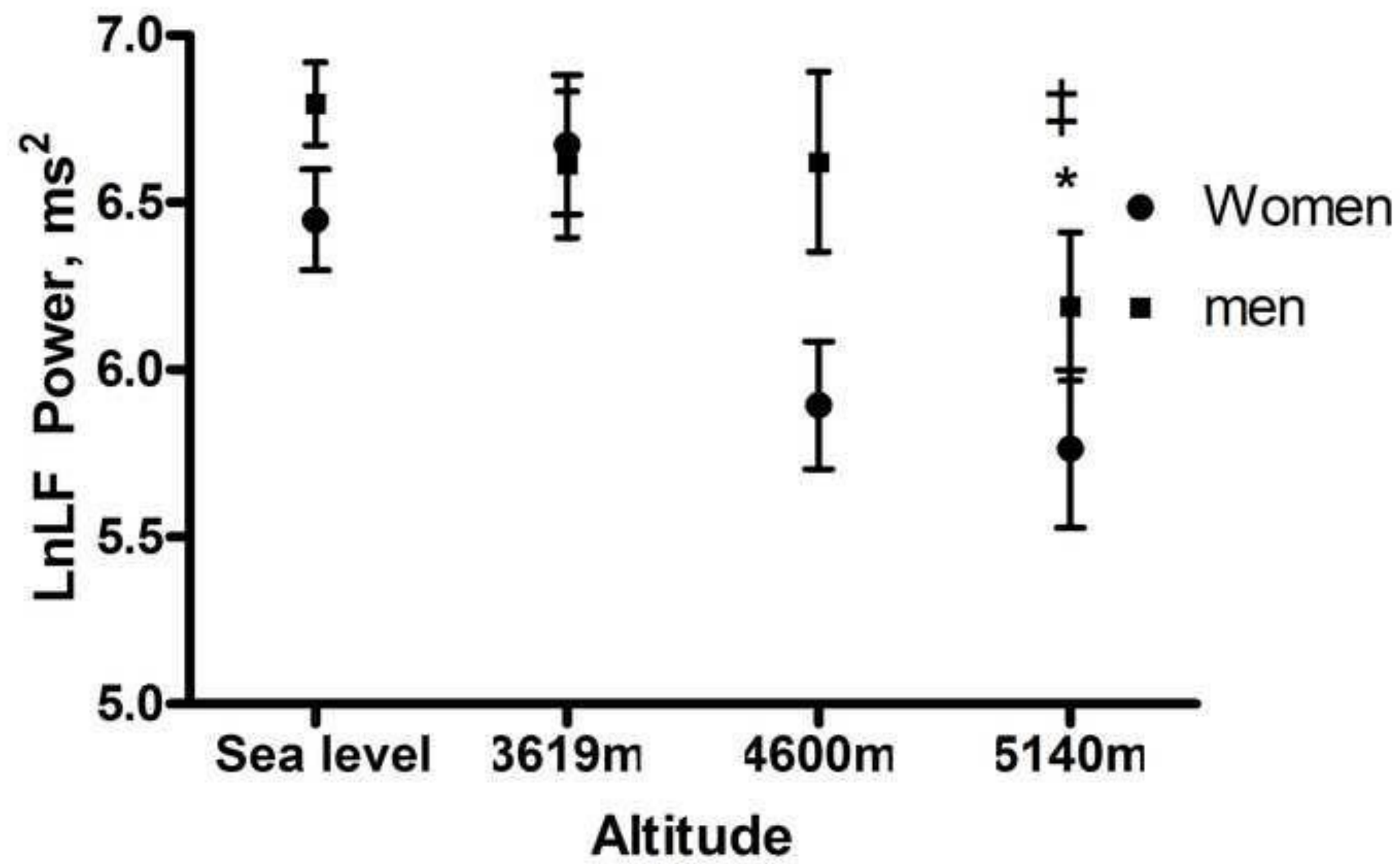

